\title{
Test anxiety, pulse rate and learning
}

ABE J. JUDSON, UTICA COLLEGE OF SYRACUSE UNIVERSITY AND MARCY STATE HOSPITAL GERALD GELBER, ESSEX COUNTY YOUTH HOUSE.

\begin{abstract}
Pulse rates of high and low test anxious Ss were obtained while they engaged in two learning tasks, one easy, one hard. Pulse rates showed a progressive decline over time and were unrelated to task difficulty nor did the two groups differ significantly on the learning tasks. However, the high anxiety group tended to have a higher pulse rate at initial exposure to the experimental situation but the difference had largely disappeared by the end of the testing session.
\end{abstract}

\section{Introduetion}

The aim of this study was to check the pulse rates of high and low test anxious Ss while they were engaged in a learning task. Although the literature on anxiety scales has proliferated remarkably in the past decade, there has been relatively little work relating these scales to physiological measures and as Sarason (1960) points out, this work has largely yielded negative results. Sarason also notes that physiological differences between high and low anxiety Ss may occur only under special conditions, such as stress or threat, just as performance differences between the two groups are most readily obtained under those conditions.

Support for this suggestion comes from a recent study of Kissel \& Littig (1962). Using Mandler \& Sarason's (1952) Test Anxiety Questionnaire (TAQ), they report a significantly higher GSR for their high anxiety group while experiencing failure although high and low anxiety groups did not differ significantly prior to failure.

It is reasonable to assume that Ss who have experienced failure in testing situations (given the motivation to succeed) will tend to develop test anxiety, but it is also reasonable to assume that the anxiety will be triggered off by the cues of the testing situation and will not require failure for their elicitation, although they may be intensified by failure. Kissel and Littig did not take their base level readings until the $S$ had been in the test situation for $15 \mathrm{~min}$. It is conceivable that the two groups may have differed initially but that these differences gradually disappeared as they adapted to the test situation during the $15 \mathrm{~min}$. Pulse rate was selected as the physiological measure because of its reliability and sensitivity (Malmo, 1959; Schnore, 1959).

\section{Method}

Subjects. The TAQ was administered to 75 female student nurses at Marcy State Hospital, Marcy, New York and the 16 high scorers and 16 low scorers were selected as Ss. TAQ scores were obtained by dividing each rating scale into six equal parts and scoring from one to six.

Pulse rate measurement. Pulse rate was measured by fitting a plastic blood pressure cuff to the left arm of the $S$ and inflating it to an initial pressure of $60 \mathrm{~mm}$.
The cuff was attached to the input of a Stoelting Mechanical Blood Pressure Transducer mounted on a Stoelting console polygraph. In those instances where blood pressure dropped considerably during the experimental period so that readings were not easily readable, pressure was added so that the initial level was restored. A continuous record of pulse rate was obtained for each $\mathrm{S}$ for the entire experimental session.

Learning tasks. The $\mathrm{S}$ sat in front of a box containing two panels, the upper one consisting of a row of eight neon lights spaced 1 in apart while the lower panel had a row of eight microswitches mounted on one side of a springloaded lever which moved downward as any switch was pressed. The S's task was to learn which switch turned off which light. The stimulus light was turned on by $E$, who sat at the control panel separated from $S$ by a screen which blocked S's view of the control and recording apparatus. The S's responses to the learning task were recorded by means of an electric typewriter connected to the microswitches so that each microswitch, when pressed, actuated a separate typewriter key. Thus it was possible to obtain a full record of the responses made to each stimulus light.

Two tasks, one easy and one hard, were given to each S. In the easy task, stimulus light and switches were paired in a simple systematic manner so that insight could easily be achieved. In this task, the correct switch was immediately to the right of the stimulus light, except for the last light which was paired with the first switch. Thus, light No. 2 was paired with switch No. 3 , light No. 6 with switch No. 7 , etc. In the difficult task, the stimulus lights were paired unsystematically with the switches.

Procedure. All Ss were tested individually. No attempt was made to induce anxiety by instructions. Ss were merely told what was required of them in the learning task and four practice lights were presented to them so that they could familiarize themselves with the operation of the apparatus. Ss were given eight trials on each task. After the eighth trial on the first task, they were informed that a new task with different light-switch pairings would be presented. Order of presentation of light stimuli was changed for successive trials but the same schedule was followed for all Ss.

Half the Ss in the high anxiety group received the easy task first and the hard task second (HE) and the order was reversed for the other half $(\mathrm{HH})$. The same procedure was followed for the low anxiety group (LE and LH). Although pulse rate readings were continuous, for purposes of analysis, readings were taken for each $S$ at the beginning of the 1st, 4th and 8th trials for both easy and hard tasks. 
TABLE I

MEAN ERRORS FOR HIGH AND LOW ANXIETY GROUPS ON THE TWO TASKS

\begin{tabular}{lcc} 
& Easy & Hard \\
\hline HE & 25.88 & 171.00 \\
HH & 14.00 & 159.00 \\
LE & 29.13 & 168.13 \\
LH & 15.50 & 186.00 \\
\hline
\end{tabular}

\section{Results}

It is evident from Table 1 that the two tasks clearly differed in difficulty. The mean number of errors for all trials on the easy task is 21.12 compared with 171.03 on the difficult task. No S completed an errorless trial on the difficult task, many did on the easy one. The high anxiety groups tend to do somewhat better than the low anxiety groups but a Lindquist Type III analysis of variance indicates that these differences are not significant. In any case, there is no evidence here for poorer performance of the high anxiety group on the hard task.

Pulse rates for the six different periods are presented in Table 2. For all groups, pulse rate is highest at the

TABLE II

PULSE RATES FOR HIGH AND LOW ANXIETY GROUPS FOR SIX DIFFERENT TIME PERIODS

\begin{tabular}{lcccccc} 
& 1 & 2 & 3 & 4 & 5 & 6 \\
\hline HE & 100.24 & 95.00 & 93.50 & 90.74 & 91.00 & 89.50 \\
HH & 99.75 & 95.14 & 92.00 & 90.25 & 87.50 & 87.00 \\
$\begin{array}{l}\text { Combined } \\
\text { (HE and HH) }\end{array}$ & 100.00 & 95.10 & 92.75 & 90.50 & 39.25 & 83.25 \\
LE & 88.50 & 88.50 & 88.00 & 84.50 & 86.00 & 84.75 \\
LH & 97.00 & 91.25 & 90.25 & 92.00 & 89.00 & 88.25 \\
$\begin{array}{l}\text { Combined } \\
\text { (LE and LH) }\end{array}$ & 92.75 & 88.38 & 89.13 & 88.25 & 87.50 & 86.50 \\
\hline
\end{tabular}

beginning of the testing period, lowest at the end. Changes in pulse rate appear to be a function of time and not of task difficulty. Because of this, the subgroups of the high and low anxiety groups are combined for a Lindquist Type I analysis of variance. The results of this analysis yield a significant $\mathrm{F}$ at the .05 level for interaction of Time Periods and Anxiety. The high anxiety group tends to have an elevated pulse rate at the beginning of the testing session but the difference between the two groups has largely disappeared by the end of the testing period.

We believe these results offer some support for the validity of the TAQ, as well as our contention that a failure experience is not essential to demonstrate physiological differences between high and low anxiety Ss. As might be expected from the item content of the TAQ, the high anxiety group does show heightened arousal upon initial exposure to the testing situation. Our failure to obtain differences in pulse rate in the two learning tasks is not necessarily evidence against the view that the TAQ is a measure of motive to avoid failure. It is possible that the anxiety inducing cues of the hard task were more than offset by anxiety reducing cues unwittingly introduced bv the $\mathrm{E}$.

\section{References}

Kissel, S., \& Littig, L. W. Test anxiety and skin conductance. J. abnorm. soc. Psychol., 1962, 65, 276-278

Lindquist, E. F. Design and analysis of experiments in psychology and education. Boston: Houghton Mifflin, 1953

Malnı, R Activation: A neuropsychological dimension. Psychol. Rev., 1959, 66, 367-386.

Mandler, G., \& Sarason, S. B. A study of anxiety and learning. $J$. abnorm. soc. Psychol, 1952, 47, 166-173.

Sarason, I. G. Empirical findings and theoretical problems in the use of anxiety scales. Psychol. Bull., 1960, 57, 403-415.

Schnore, M. M. Individual patterns of physiological activity as a function of task differences and degree of arousal. J. exp. Psychol., 1959, 58, 117-128. 